\title{
Understanding the Influence of Shunts in the I-V Curves and Electroluminescence of Multijunction Solar Cells
}

\author{
I. Lombardero $^{1, \text { a) }}$ and C. Algora ${ }^{1}$ \\ ${ }^{1}$ Instituto de Energía Solar, Universidad Politécnica de Madrid, 28040 Madrid, Spain, http://www.ies.upm.es/ \\ a) Corresponding author: ivan.lombardero@ies.upm.es
}

\begin{abstract}
The influence of shunts on multijunction solar cells cannot be directly extrapolated from their effect on single junction solar cells. It is shown that the rules of thumb for single junction solar cells can mislead to wrong diagnosis on multijunction solar cells when they are only partially shunted. In order to properly assess their performance, three dimensional simulations have been carried out using equivalent electrical circuits. In this work, we point out the differences between completely and partially shunted multijunction solar cells under different regimes and evaluate the use of I-V curves and electroluminescence as valid tools to detect the existence of shunts. A straightforward application of this work is its use in reliability analysis, allowing an undoubtedly identification of shunts at both the solar cell manufacture and on-field operation.
\end{abstract}

Keywords: Multijunction solar cells, solar cell simulation, shunted solar cells

\section{INTRODUCTION}

It is commonly accepted that solar cell losses can be identified depending on the region affected of the illumination $\mathrm{I}-\mathrm{V}$ curve. Under this assumption, deviations from the ideal I-V curve shape close to $0 \mathrm{~V}$ (short circuit conditions) are related to shunt effects, deviations around the open circuit voltage are connected to ohmic losses while the $V_{\mathrm{OC}}$ and $I_{\mathrm{SC}}$ values achieved are linked to the recombination processes taking place within the solar cell. These rules of thumb, which associate the shape of the illumination I-V curve with a particular type of loss, are based on the circuit model of a single junction solar cell. However, the use of these rules of thumb to explain the performance of a multijunction solar cell (MJSC) may induce erroneous conclusions. In particular, the rule of thumb related to shunt effects in single junction solar cells cannot be always applied to MJSCs. promoting mistaken decisions when evaluating new multijunction solar cell architectures, manufacture yield issues, or degradation of on-field devices.

The effect of shunt resistances in MJSCs has been mainly studied regarding its influence on the current generation or the spectral response measurement of the subcells [1-7]. However, in MJSCs, shunt resistance effects can influence the $V_{\mathrm{OC}}$ and $P_{\mathrm{MAX}}$ voltage ranges without affecting the current generation (similar to shunted silicon solar cells inside a module [8]). Only recently there have been efforts pointing out the influence of the shunt resistance on the $F F$ or the $V_{\text {OC }}$ of a MJSC [9]. In this work, we go in depth of preliminary results [10] which pointed out the difference between the shunt impact in single and multijunction solar cells. We provide a deeper explanation of the observed effect (partially vs completely shunted solar cells) and enhance the comprehension about the influence of shunts in the $V_{\mathrm{OC}}$ and the $F F$. In particular, we assess the shunt resistance impact on MJSCs by investigating their I-V curves (dark and illumination) and their electroluminescence (EL) by using a three-dimensional (3D) model based on equivalent electrical circuits [11,12]. The paper is structured as follows: first the influence of each shunted subcell on the overall MJSC's performance under illumination conditions is evaluated as a function of the shunt resistance in our simulations. Then, the effects of shunts as a function of the light concentration and under different spectral conditions on a MJSC are assessed as well. Finally, dark I-V and EL simulations are used to demonstrate that these measurements can be used to univocally identify shunts, in opposition to illumination I-V measurements, 
providing a practical shunt detection for reliability assessment at the manufacturing stages [13] or for on-field devices.

\section{METHODS}

The influence of shunts on MJSCs has been assessed simulating equivalent electrical circuits. This approach emulates the physical performance of a solar cell by means of equivalent circuits where each device resembles a different physical process (carrier generation/recombination, leakage currents and ohmic losses, see Table 1 for further information). One and two dimensional (1D and 2D) models have been used to simulate solar cell performance for years [14]. However, these models cannot emulate the actual performance of real solar cells when considering the metal grid, perimeter recombination or non-homogenous illumination conditions. In order to achieve a high simulation accuracy, models based on three dimensional (3D) distributed circuits have been widely used to simulate the solar cell performance, being their suitability extensively proved [15-18]. Therefore, 3D equivalent circuits are used in this work, made up of unit cells related to different electronic circuits according to the type of unit cell (active area, metal or perimeter) as shown in Fig. 1 d-f. Each unit cell is connected to the contiguous ones to build the whole circuit resembling the solar cell. GaInP/Ga(In)As/Ge standard triple junction solar cells are simulated with a $5.5 \times 5.5 \mathrm{~mm}^{2}$ area and a comb-like metal grid with an efficiency of $40 \%$ at $900 \times$ (Figure 1c). The minimum size of a unit cell is as small as $1 \mu \mathrm{m}^{2}$ althoguh different sizes are used to minimize the computation time while keeping the simulation accuracy. The parameters used in the model through these paper, unless otherwise noted, are shown in Table 2 and Table 3 [19]. The 3D circuit is solved using Silvaco's SmartSpice proprietary software [20]. Although 1D and 2D models would have been good enough for the assessment of the shunt influence under illumination (where homogeneously shunted subcells have been used to ease the understanding of the underlying behavior), the evaluation of dark I-V and EL as valid tools to detect shunts in MJSC needs the simulation of more realistic conditions (i.e. non-homogenous shunts). Therefore, 3D circuits are required to reproduce this behavior faithfully and consequently, all simulations throughout the paper are 3D in order to be consistent.

Current sources are used to simulate carrier collection (which is intimately related to the carrier photogeneration) while diodes emulate the recombination currents. They have been split into recombination at the neutral regions and at the space charge region. Nevertheless, other recombination processes such as those ones taking place at the perimeter or at any interface inside the semiconductor structure, or different recombination processes (radiative, SRH, Auger), could have been considered adding more diodes [17]. Shunt and ohmic losses are simulated using parallel resistances for the former and series ones for the latter (whether vertical or lateral). Non-ohmic losses are not considered as standard solar cells have ohmic contacts and tunnel junctions operating in their ohmic regimes. Leakage currents, commonly referred simply as shunts, are assumed to have an ohmic behavior as well. It must be noticed that, although non-ohmic shunts [13,21] and breakdown voltages [1,3] have been previously reported, they are not considered in this work since they are not common on typical MJSCs or they do not strongly influence the power generation under standard conditions.

Table 1. Main physical processes in a solar cell and the electronic devices used to simulate them in our 3D model. The corresponding way of degrading the solar cell is pointed out as well.

\begin{tabular}{ccc}
\hline $\begin{array}{c}\text { Physical } \\
\text { process }\end{array}$ & $\begin{array}{c}\text { Equivalent device in the } \\
\text { electrical circuit }\end{array}$ & Degradation process \\
\hline $\begin{array}{c}\text { Carrier } \\
\text { collection }\end{array}$ & Current source & $\begin{array}{c}\text { A decrease in the collection of the photogenerated carriers is } \\
\text { simulated by reducing the current provided by the source }\end{array}$ \\
$\begin{array}{c}\text { Carrier } \\
\text { recombination }\end{array}$ & $\begin{array}{c}\text { Diode } \\
\text { (different types of diodes used } \\
\text { for each type of recombination) }\end{array}$ & $\begin{array}{c}\text { An increase in the recombination currents is simulated as an } \\
\text { increase in the reverse saturation current of the diodes (or by } \\
\text { adding new diodes accounting for new types of } \\
\text { recombination) }\end{array}$ \\
Ohmic loss & Series resistance & $\begin{array}{c}\text { An increase in the ohmic losses is simulated as an increase } \\
\text { of one or more of the different types of series resistance }\end{array}$
\end{tabular}


Leakage current
Shunt resistance
An increase in the leakage current is simulated by decreasing the shunt resistances

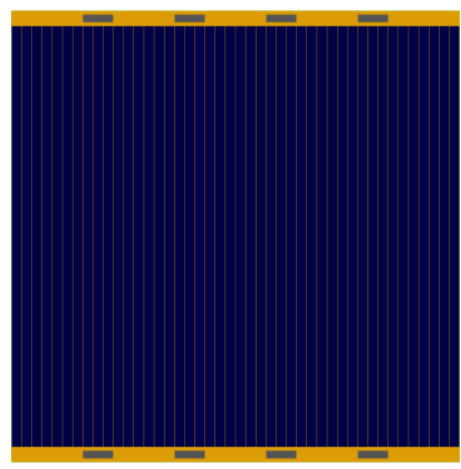

(a)

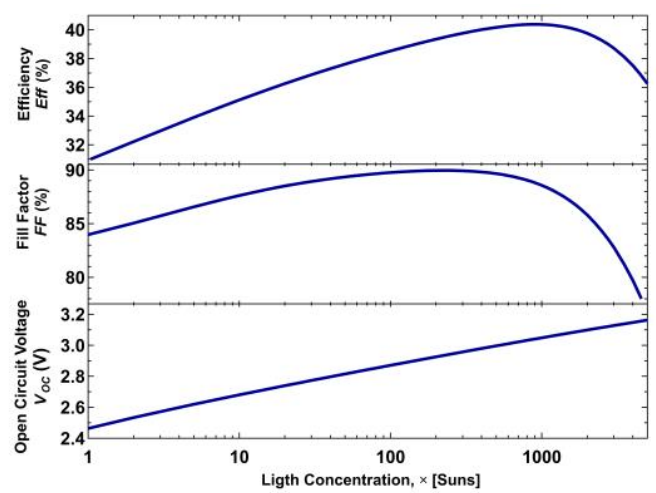

(c)

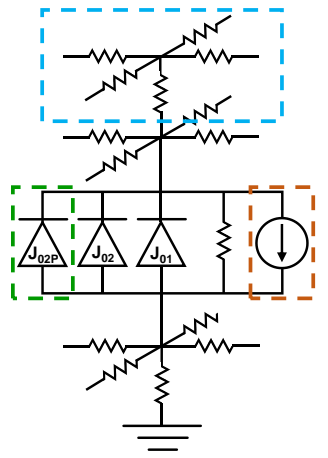

(b)

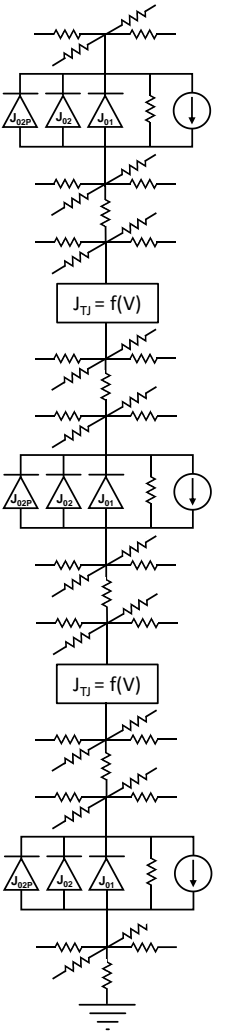

(d)

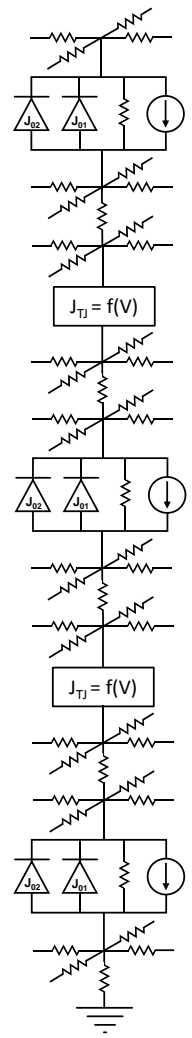

(e)

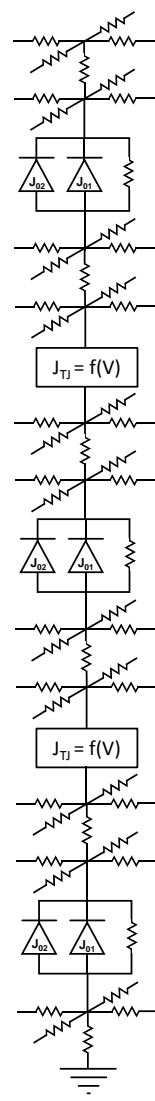

(f)

Figure 1. Layout of the model used to carry out the simulations: a) Front view of the simulated solar cell. b) Single junction solar cell equivalent circuit, the characteristic devices of each circuit (illuminated, metal or perimeter, see figures d, e and f) are highlighted in different colors (orange blue and green respectively). c) Performance (efficiency, fill factor and open circuit voltage) as a function of concentration for the simulated $\mathrm{GaInP} / \mathrm{Ga}(\mathrm{In}) \mathrm{As} / \mathrm{Ge}$ triple junction. Equivalent circuits of the triple junction solar cell for d) the perimeter e) the active area, f) the metalized area.

Table 2. Main parameters of the semiconductor structure of the triple junction solar cell used in the simulations. The photogenerated currents $\left(I_{\text {Photogenerated }}\right)$ have been calculated from standard EQEs under AM1.5d.

\begin{tabular}{lccc}
\hline Parameter & GaInP & Ga(In)As & Ge \\
\hline $\boldsymbol{J}_{\mathbf{0 1}}\left(\mathrm{A} / \mathrm{cm}^{2}\right)$ & $9.5 \cdot 10^{-25}$ & $6 \cdot 10^{-20}$ & $2.5 \cdot 10^{-5}$ \\
$\boldsymbol{J}_{\mathbf{0 2}}\left(\mathrm{A} / \mathrm{cm}^{2}\right)$ & $1 \cdot 10^{-13}$ & $1 \cdot 10^{-30}$ & $1 \cdot 10^{-30}$ \\
$\boldsymbol{J}_{\mathbf{0 2 P e r}}\left(\mathrm{A} / \mathrm{cm}^{2}\right)$ & $1 \cdot 10^{-30}$ & $8.5 \cdot 10^{-12}$ & $1 \cdot 10^{-30}$ \\
$\boldsymbol{R}_{\text {SheetEmitter }}(\Omega / \square)$ & 300 & 325 & 782 \\
$\boldsymbol{R}_{\text {Shunt }}\left(\Omega \cdot \mathrm{cm}^{2}\right)$ & $1 \cdot 10^{6}$ & $1 \cdot 10^{6}$ & $1 \cdot 10^{6}$
\end{tabular}


$\boldsymbol{I}_{\text {Photogenerated }}\left(\mathrm{mA} / \mathrm{cm}^{2}\right)$

$\boldsymbol{R}_{\text {Tunnel }}\left(\Omega \cdot \mathrm{cm}^{2}\right)$
$3 \cdot 10^{-4}$
14.5

20

Table 3. Main parameters of the metallic contact used in the simulations

\begin{tabular}{cc}
\hline $\begin{array}{c}\text { Metal Sheet Resistance } \\
(\Omega / \square)\end{array}$ & $\begin{array}{c}\text { Specific Front Contact } \\
\text { Resistance } \\
\left(\Omega \cdot \mathrm{cm}^{2}\right)\end{array}$ \\
\hline $150 \cdot 10^{-3}$ & $1 \cdot 10^{-5}$ \\
\hline
\end{tabular}

\section{RESULTS}

\subsection{Impact of Shunts on the MJSC I-V Under Illumination}

As aforementioned the impact of shunts on MJSCs have been assessed by 3D equivalent circuits simulations using the parameters depicted in Table 2 and Table 3 unless otherwise noted. The scenarios simulated to address the influence of shunts are:

a) Illumination I-V curve

b) $F F$ and $V_{\text {OC }}$ evolution as a function of concentration

c) $F F$ and $V_{\mathrm{OC}}$ as a function of the photogeneration ratio between subcells

\subsubsection{Illumination I-V Curve}

The degradation caused on the MJSC performance by the presence of shunts has been simulated by decreasing the shunt resistance homogenously throughout the whole area of each subcell independently (in a MJSC), as well as for the whole device. Recombination currents and ohmic losses have also been swept independently. In order to evaluate which single junction behavior can be extrapolated to MJSCs, a GaInP single junction solar cell (with the same parameters as those of the GaInP top subcell of the MJSC) has been also simulated for comparison (Figure 2). Diode ideality factor remains unchanged as it would only change the main voltage range of impact of a diode but not the way it changes the I-V curve shape. 


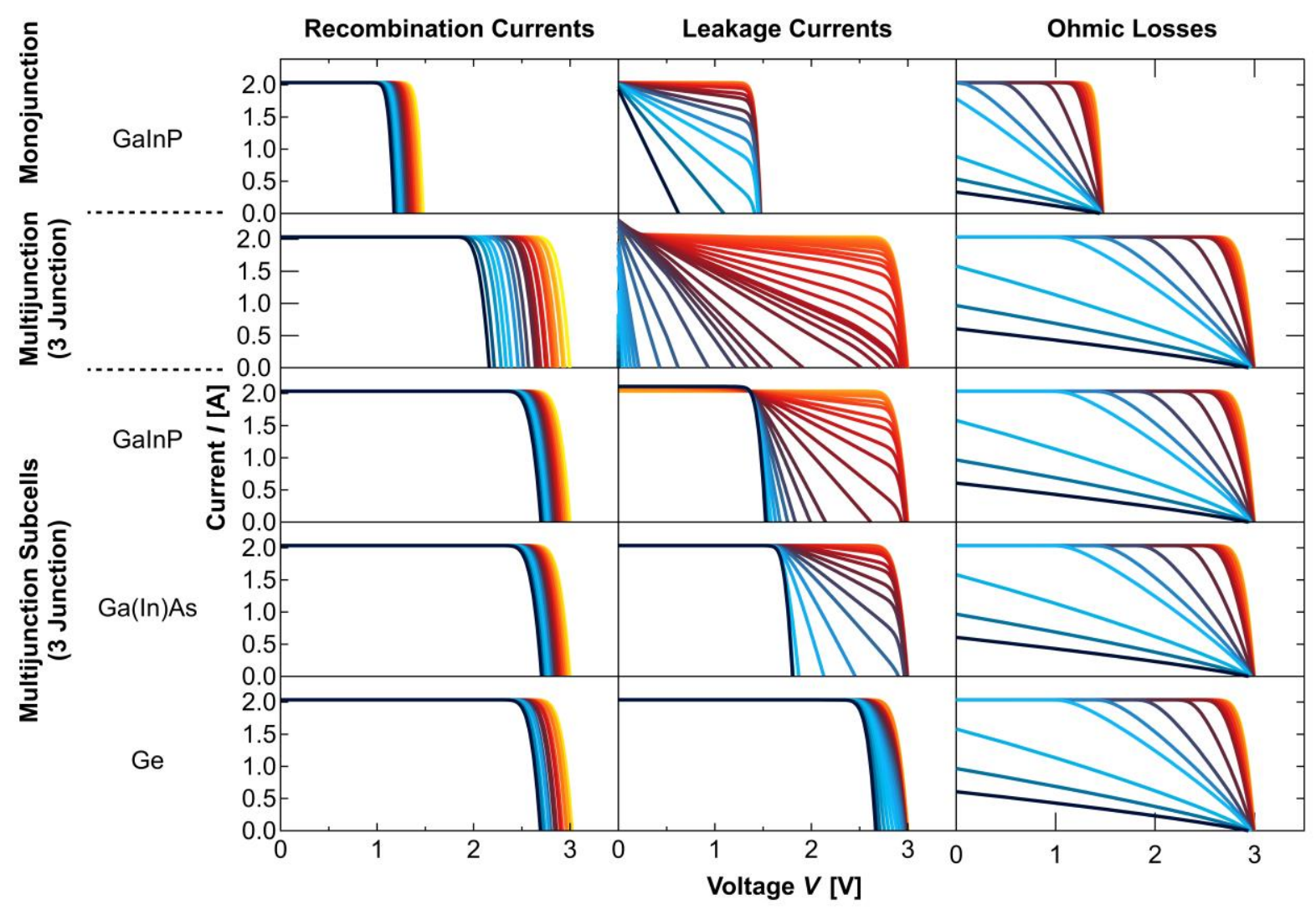

Figure 2. Impact of recombination currents, shunt and ohmic losses on a GaInP single junction (top), a triple junction (middle) and on each subcell of a triple junction solar cell (bottom).

Figure 2 shows that the impact of an increase of both, the recombination currents and the ohmic losses, can be extrapolated directly from single to MJSCs. An increase in the recombination current causes a drop of the $V_{\mathrm{OC}}$ while the increase in the ohmic losses causes a decrease of the slope at $V_{\mathrm{OC}}$ (affecting the $I_{\mathrm{SC}}$ operation point for very high ohmic losses). However, the effect of an increase of the leakage currents needs a more thorough analysis. When the whole MJSC is shunted, the trend is similar to the one of the single junction (i.e. increasing the I-V curve slope at $I_{\mathrm{SC}}$ and affecting $V_{\mathrm{OC}}$ for highly shunted devices). Nonetheless, when shunts are only present in one subcell a different effect is observed. This means that the shunt impact analysis has to be split into partially shunted solar cells (when not all subcells are shunted) and completely shunted solar cells (when all subcells are shunted).

The most obvious difference between partially and completely shunted solar cells is that the shunt effect is not seen at $0 \mathrm{~V}\left(I_{\mathrm{SC}}\right)$ but at higher voltages instead. In particular, the effect is seen close to the sum of the $V_{\mathrm{OC}}$ of the other (non-shunted) subcells. This is a direct consequence of the series-connection among subcells, which implies that the same current must pass through all subcells. For the non-shunted subcells, the current generation only decreases substantially for voltages close to their $V_{\mathrm{OC}}$. Thus, the shunted subcell is operating at the same voltage until the other subcells start to decrease their current generation, making the shunt noticeable. $V_{\mathrm{OC}}$ and $F F$ are two key parameters to understand the difference between partially and completely shunted solar cells. The evolution of these parameters with the shunt resistance is depicted in Figure 3, which depicts 4 possible cases regarding the $V_{\mathrm{OC}}$ and $F F$ degradation. 


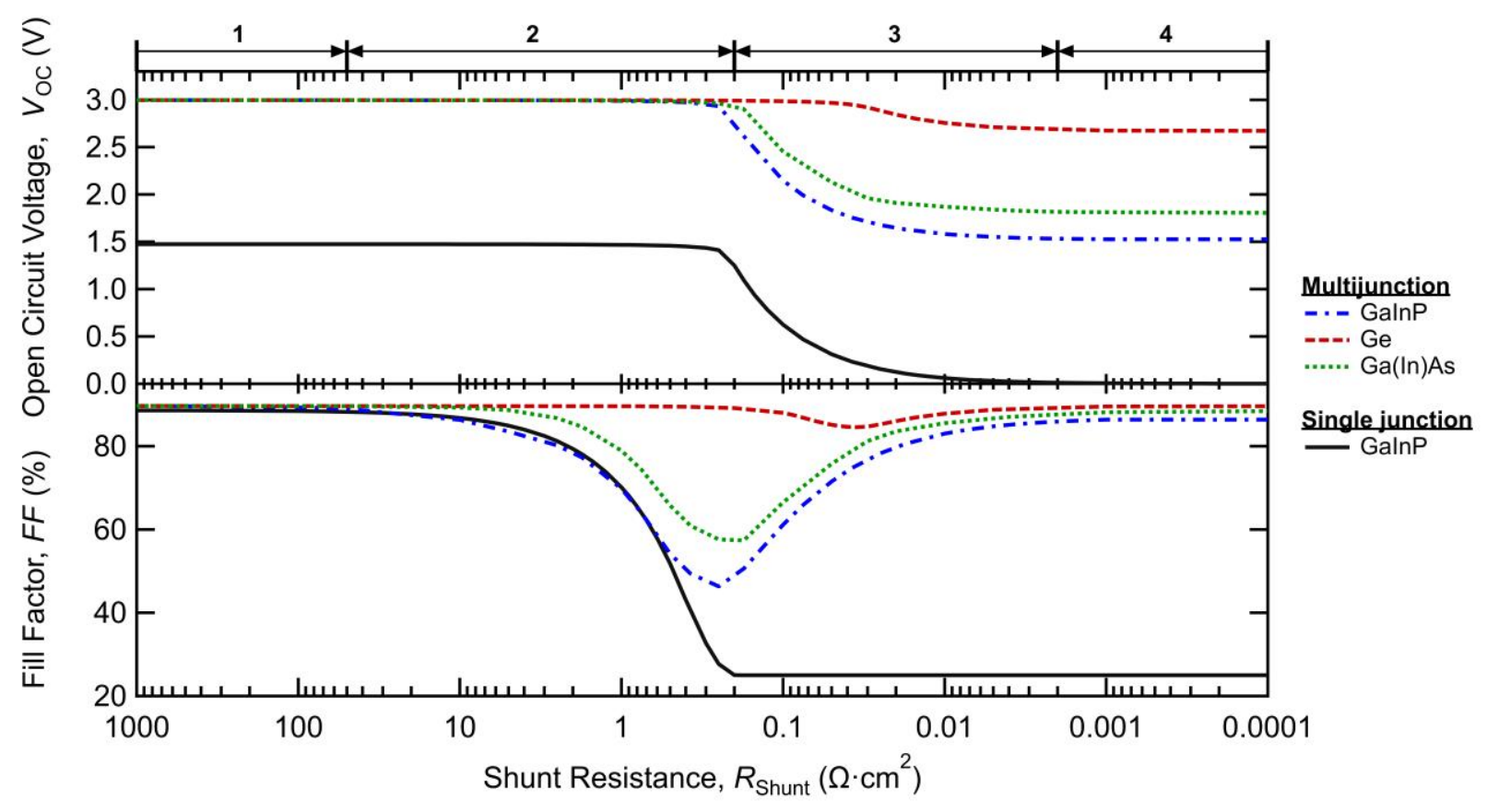

Figure 3. Fill factor and open circuit voltage variation as a function of the shunt resistance in a GaInP single junction as well as in each subcell of a MJSC (GaInP/Ga(In)As/Ge). Four cases can be distinguished and are marked on top of the figure: 1$) \mathrm{FF}$ and $V_{\mathrm{OC}}$ are not degraded by the shunt, 2) FF is degraded while, $V_{\mathrm{OC}}$ remains constant, 3) FF saturates at $25 \%$ in the single junction while for the MJSC FF increases, $V_{\mathrm{OC}}$ decreases for both, 4) FF remains constant at $25 \%$ and $V_{\mathrm{OC}}$ decreases to 0 asymptotically in the single junction while for the MJSC FF and $V_{\mathrm{OC}}$ saturate at those ones of the other (non-shunted) subcells. The ranges depicted are only illustrative to the eye, as the effects caused by each subcell become noticeable under different shunt resistances values.

The first case corresponds to a negligible leakage current in comparison to the current generation and therefore, there is no influence on the I-V curve.

The second case could be easily recognized as a shunt effect (in the absence of any other degradation), as the $V_{\mathrm{OC}}$ and the slope of the I-V curve at $V_{\mathrm{OC}}$ are not affected (see for instance scenario $c$ in Figure 4). Therefore, an increase of the resistive losses or the recombination currents can be discarded. $F F$ and $V_{\mathrm{OC}}$ of completely and partially shunted solar cells follow the same trend in this case, where the $F F$ decreases while the $V_{\mathrm{OC}}$ remains constant. $F F$ decreases up to $25 \%$ for a completely shunted solar cell while for a partially shunted solar cell it depends on the relative voltage contribution of the shunted subcell to the total $V_{\mathrm{OC}}$ (see APPENDix A: maximum INFLUENCE OF a SHUNTED SUBCELL ON THE OVERALL FF OF AN IDEAL MJSC). That means that shunts in top/middle subcells will degrade the $F F$ more severely than if the shunted subcell were the bottom one.

The third case shows different trends for completely and partially shunted solar cells. While completely shunted solar cells clearly show a degraded I-V shape (straight line between $I_{\mathrm{SC}}$ and $V_{\mathrm{OC}}$, being undistinguishable if it has been degraded by ohmic losses or shunts), the partially shunted solar cell resembles the I-V shape of a solar cell with ohmic losses (flat I-V curve at $I_{\mathrm{SC}}$ with a decrease of the slope at $V_{\mathrm{OC}}$, see scenario $d$ in Figure 4). As the current leaked by the shunt increases, the I-V shape of the partially shunted solar cell tends to resemble more recombination losses and less ohmic losses ( $V_{\mathrm{OC}}$ decreases while increasing the slope at $V_{\mathrm{OC}}$ ). Moreover, as shown in Figure $3, F F$ recovers for very low shunt resistances, which would not be expectable from single junction (completely shunted) solar cell rules of thumb. This makes it harder to intuitively recognize shunt effects when they are so intense that affect the $V_{\mathrm{OC}}$ operation point. Therefore, this case (as well as the fourth one) could be misunderstood as a mix of ohmic losses and recombination currents increase instead of the consequence of a shunt.

The fourth case shows the situation where the shunt dominates the whole junction. For completely shunted solar cells, this means a decrease of $V_{\mathrm{OC}}$ towards $0 \mathrm{~V}$ keeping the $F F$ constant at $25 \%$. On the other hand, the $F F$ of a 
partially shunted solar cells recovers up to the one corresponding to the non-shunted solar cells (which could be even greater than the initial $F F$ ) while $V_{\mathrm{OC}}$ becomes as low as the sum of the non-shunted junctions $V_{\mathrm{OC}}$.

It can be demonstrated that the maximum $F F$ drop depends linearly (for an ideal solar cell) on the relative contribution of the subcell to the total $V_{\mathrm{OC}}$ (see Appendix A), which is clearly seen in Figure 3. Considering this, shunts in low bandgap subcell will make the illumination I-V resemble the shape of an I-V degraded by recombination currents (see "Recombination currents" and "Leakage currents" degradations for the Ge subcell in Figure 2 or, scenario $a$ in Figure 4). This is of particular importance if we take into account that the development of new MJSCs is pointing to four, five or even six junction architectures [22-24]. Consequently, the relative contribution of each subcell to the total $V_{\mathrm{OC}}$ of the multijunction will decrease. Besides, the upcoming MJSC will include new junctions with low bandgaps.

An interesting fact to point out is that an $I_{\mathrm{SC}}$ increase could be observed if the shunted subcell is the one with the lowest photocurrent inside the MJSC (see the shunted GaInP subcell in the MJSC in Figure 2, and check Table 2 to see the photocurrents of each subcell). Under such circumstances, the limiting current subcell will be biased under negative voltages at $I_{\mathrm{SC}}$ (multijunction at $0 \mathrm{~V}$ ), increasing its current generation as it is shunted. If it is still the subcell limiting the current or not, will depend on how shunted it is and how much voltage can provide the other subcells before becoming the limiting subcells (which might depend on the irradiance conditions [7]). It is important to keep this in mind as high concentration solar cell characterization is usually quite challenging due to the complexity of achieving spectral matching conditions for all subcells [25-27]. Otherwise, this current increase could be misunderstood as incorrect measurements conditions (i.e. non-spectral matched) or other measurement artifacts. Nevertheless, the main conclusions do not change no matter whether the shunted subcell is the limiting one or not, as can be seen in Figure 3, where GaInP (which is the limiting subcell) and GaAs subcell follow similar trends. It is true that the hindering caused in the FF will vary depending on the photogeneration of each subcell (which is further analyzed in Section 3.1.3), but neither will do the general trend nor the conclusions stated up to now.

A summary of all the effects that could be caused by shunts in a partially shunted MJSC is presented in Table 4 together with the corresponding explanation for completely and partially shunted solar cells.

Table 4. Summary of the effects that can be seen in the illumination I-V curve of a MJSC and their possible explanations. Effect observed Completely shunted MJSC Partially shunted MJSC

\section{Negligible $V_{\mathrm{OC}}$ loss and small slope increase at $V_{\mathrm{OC}}$ (Figure 4 Scenario A)}
$V_{\mathrm{OC}}$ loss and negligible slope increase at $V_{\mathrm{OC}}$ (Figure 4 Scenario B)
$V_{\mathrm{OC}}$ loss and high slope increase at $V_{\text {OC }}$ (Figure 4 Scenario D)
High $V_{\mathrm{OC}}$ loss and small slope increase at $V_{\mathrm{OC}}$ (Figure 4 Scenario E)

$I_{\mathrm{SC}}$ increase (Figure 4 Scenario C, D and E)
Slight series resistance and negligible recombination current increase

Negligible series resistance and slight recombination current increase

High series resistance and slight recombination current increase

Slight series resistance and high recombination currents increase

Wrong measurement conditions

(Lack of spectral matching conditions)
Low voltage subcell considerably shunted

Low voltage subcell extremely shunted

High voltage subcell considerably shunted

High voltage subcell extremely shunted

Shunted subcell generates the lowest photocurrent of the multijunction (negatively biased at $\left.I_{\mathrm{SC}}\right)$ 

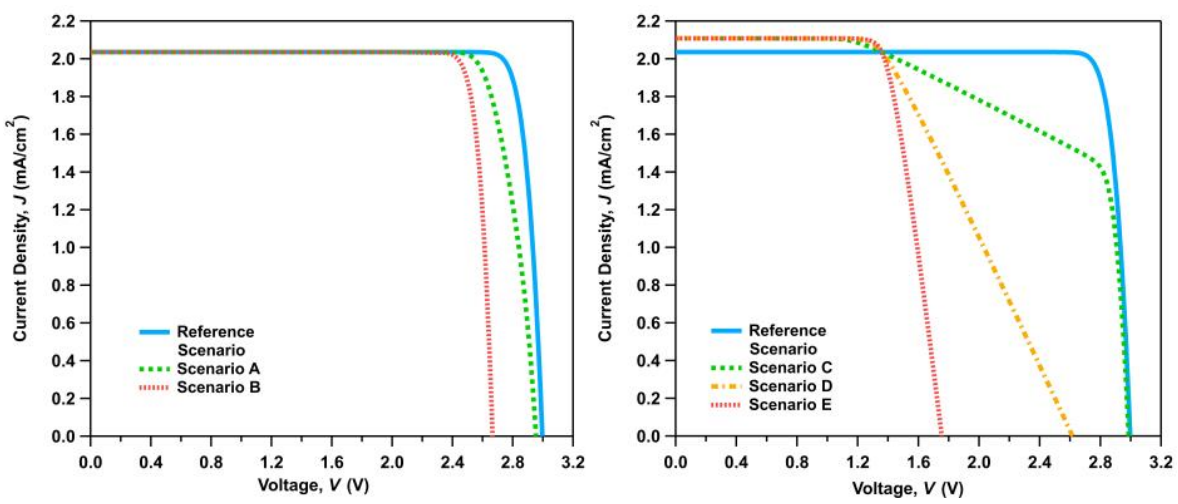

Figure 4. Different scenarios of a shunted triple junction solar cell, see Table 2.

\subsubsection{Shunt Impact as a Function of Concentration}

The influence of shunts in the $F F$ can be estimated from empirical formulas [28] for single junction solar cells. These formulas take into account the shunt effect on the $F F$ by decreasing it in a given factor. Nevertheless, the $F F$ of a MJSC follows a more complex trend, decreasing and increasing as concentration increases. This trend is depicted in Figure 5, where five $F F-V_{\mathrm{OC}}$ regions are observed as a function of concentration (no variation in the spectrum has been considered for simplicity). At very low concentrations (region 1), the partially shunted MJSC has a lower $V_{\mathrm{OC}}$ and a higher $F F$ than the non-shunted one. This is due to the fact that the shunted subcell is completely dominated by the shunt, avoiding any voltage contribution nor limiting the $F F$ in any way. Then, the shunted subcell starts to increase its voltage, but at the cost of decreasing the fill factor of the MJSC (region 2). Then, at medium concentrations (region 3 ) the overall voltage of the shunted solar cell starts to achieve the voltage of the non-shunted solar cell and its $F F$ starts to recover. Afterwards, $F F$ and $V_{\mathrm{OC}}$ reach the same values of the non-shunted solar cell when the current generation is high enough (region 4). Finally, for ultra-high concentrations, series resistance dominates the solar cell performance forcing $F F$ to decrease again (region 5). The actual concentration ranges for low, medium and high concentrations ranges depends on how deleterious the shunt effect is and how much current the series resistance allow to generate without degrading the performance. This can be observed in Figure 5 where the evolution for the same solar cell with three different shunts is depicted.

It is worth mention that region 3 is particularly deceiving as it has a $V_{\mathrm{OC}}$ close to the non-shunted one, but it still has a low $F F$, resembling the case of solar cell dominated by series resistance losses. Moreover, for some concentration levels in region 3, the higher the concentration the lower the $F F$ and the higher the $V_{\mathrm{OC}}$, showing a similar behavior to that of a series resistance limited solar cell (i.e. the change from region 2 to 3 could be misunderstood as region 5). 


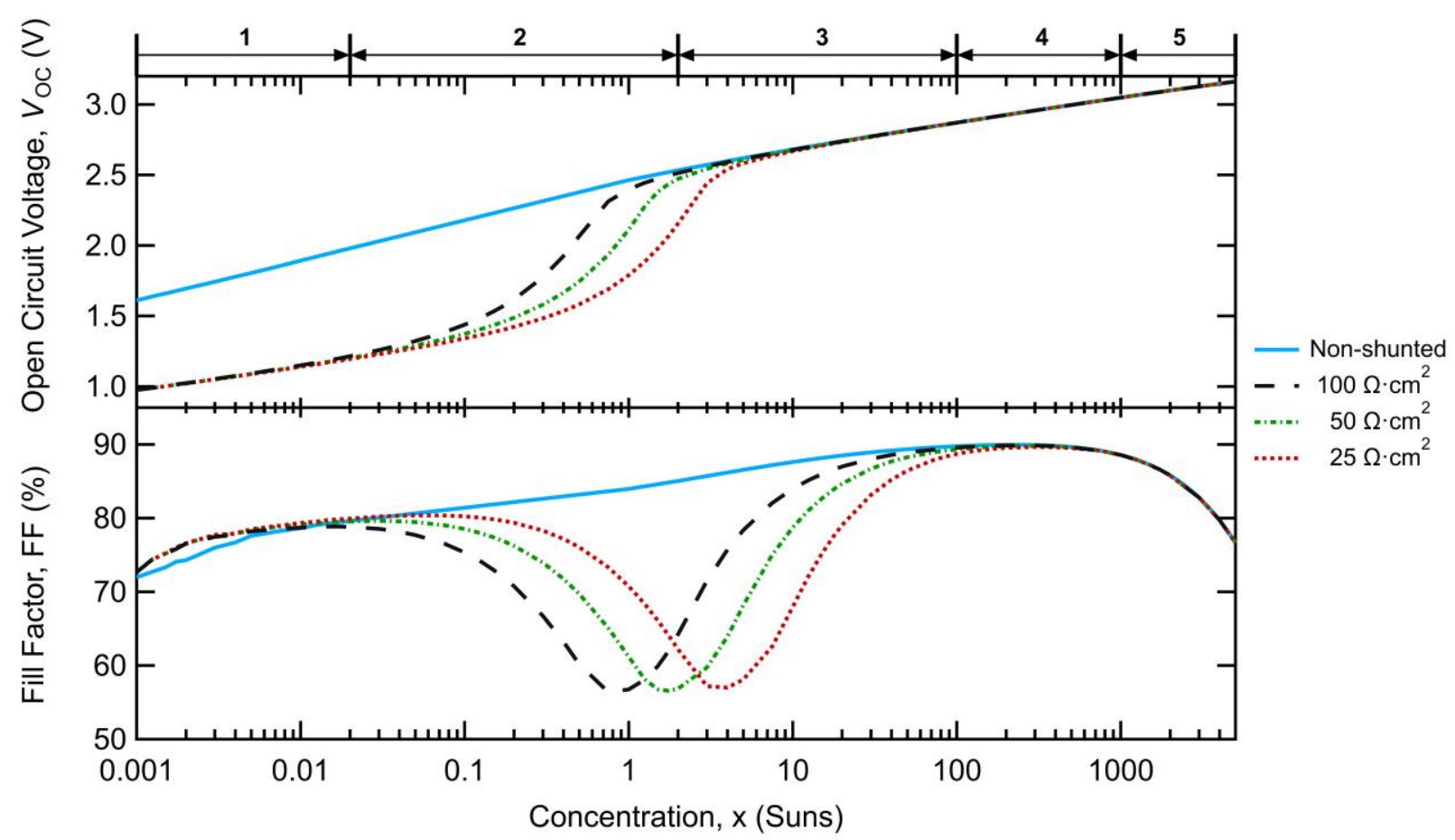

Figure 5. Evolution of $F F$ and $V_{\mathrm{OC}}$ for a triple junction solar cell, with the middle subcell shunted at three different values. A non-shunted solar cell is also shown for comparison. It must be highlighted that the concentrations for each region will depend on the shunt values. 1. Lower $V_{\mathrm{OC}}$ and higher FF, 2) FF decreases and $V_{\mathrm{OC}}$ increases, 3) $V_{\mathrm{OC}}$ reaches the non-shunted value and $F F$ starts to recover, 4) $F F$ reaches the non-shunted value, 5) Series resistance losses make $F F$ decrease again. No change in the photogeneration ratios between subcells as the concentration varies has been considered for simplicity.

\subsubsection{Over/Under Current Generation on the Impact of the Shunt Resistance on the I-V}

The effect of a shunted subcell on the overall MJSC performance depends on how much current it generates in comparison to the other subcells. Figure 6 compares the evolution of $F F$ and $V_{\mathrm{OC}}$ of a MJSC as the Ge subcell gets shunted for two different irradiation levels for that subcell (i.e. no change in the irradiation for the two upper subcells is considered). A similar trend as the ones previously shown is followed in both cases ( $V_{\mathrm{OC}}$ loss and FF dip which is recovered for highly shunted subcells). The over-illumination has two effects: first, it limits the dip amplitude in the $F F$, and second, it lowers the shunt resistance value needed for the dip appearance. A higher photogeneration implies that more current needs to be leaked by the shunt before it affects the multijunction solar cell I-V curve under illumination, which explains why a lower shunt resistance is needed to see its influence. Lower shunt resistances diminish the influence of the shunted subcell on the slope of the I-V curve at $V_{\mathrm{OC}}$, which explains the lower dip in the FF.

This is of application in standard triple junction lattice-matched solar cells where the Ge subcell usually generates much more current than the two upper subcells and thus making the overall MJSC performance more insensitive to shunts in the Ge subcell. However, this is not the case of Ge subcells in solar cells with four or more junctions which will not have a significant overcurrent generation. Therefore, deleterious effects caused by shunted Ge subcells will be more damaging if the Ge subcell does not have a photocurrent excess. Conversely, the higher the number of junctions the higher the total $V_{\mathrm{OC}}$ and consequently the lower the FF degradation caused in the MJSC by a shunted Ge subcell as demonstrated in Appendix A (it is worth mentioning that the FF dip does not even reach $80 \%$ even if the Ge photocurrent is halved in a standard triple junction). Therefore, whether a shunted Ge subcell actually degrades more a triple junction or MJSC with more junctions will depend on many parameters (total $V_{\mathrm{OC}}$, photogenerated current by each subcell, etc.) and is out of the scope of this paper. 


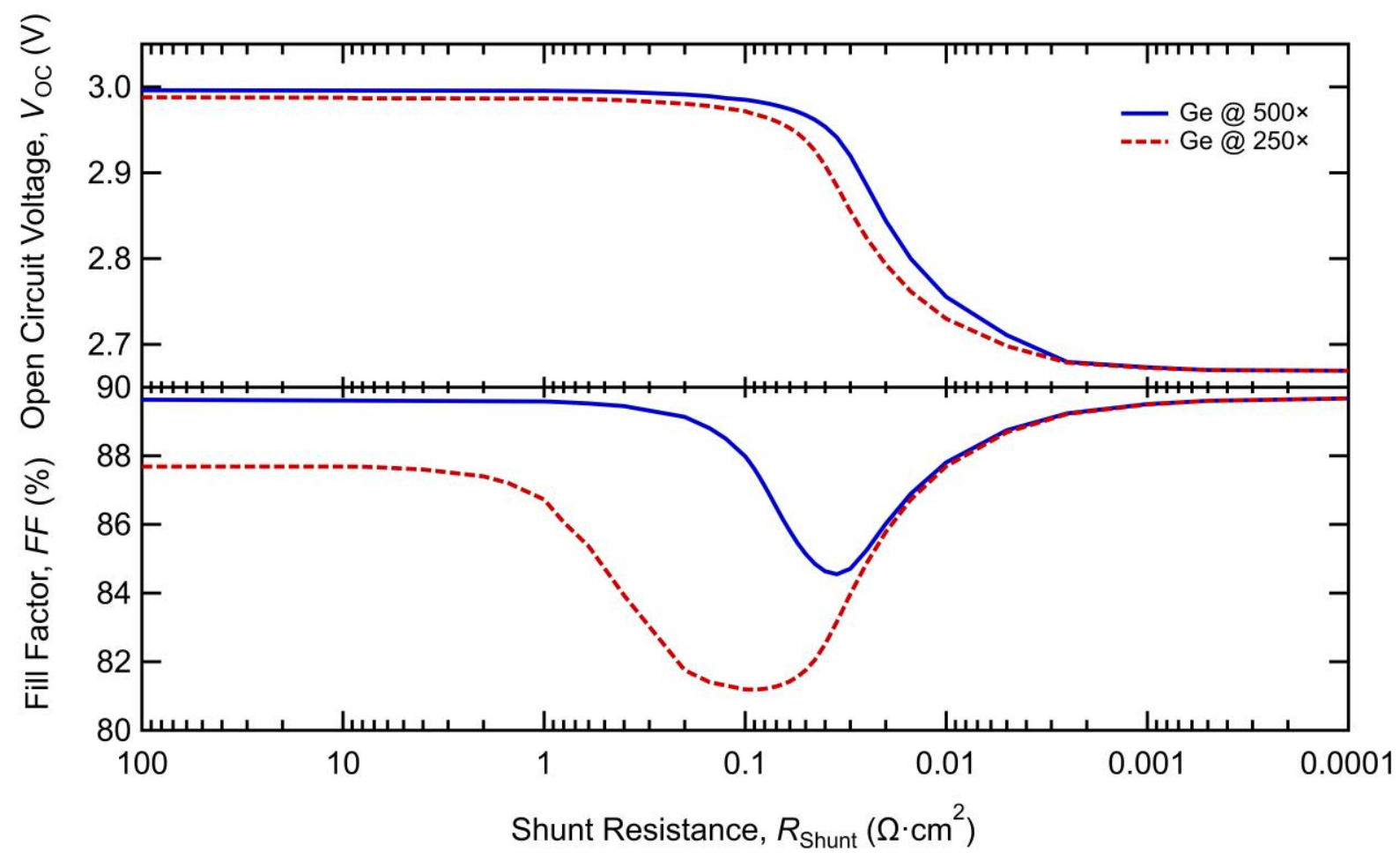

Figure 6. $F F$ and $V_{\mathrm{OC}}$ evolution as a function of the shunt resistance for the Ge subcell at two different concentration levels (250 and 500x). The rest of subcells are illuminated at $500 \times$.

\section{DETECTION OF SHUNTS}

EL and photoluminescence (PL) have been reported to be useful techniques to detect shunts in triple junction solar cells [29-31]. EL is of particular importance since it requires simple equipment and it can be used to characterize on-field devices. Another very spread technique is dark I-V measurements (although it is not useful to detect the affected area), since it is even easier to carry out than EL and it provides accurate information about whether a shunt is present or not. Both techniques are analyzed below as tools to detect and assess the effect of shunts.

\subsection{Dark I-V Curves}

Figure 7 shows the simulated dark I-Vs and illumination I-Vs of a MJSC varying the shunt resistances of the top subcell beneath the external connections (similar to the one depicted in Figure 8 - left). A voltage loss on the dark I-V curve appears corresponding to the voltage contribution of the shunted subcell. As the voltage bias increases the loss is recovered, achieving the same I-V curve that it would have had without any shunt. The voltage needed to recover the performance increases as the shunt resistance decreases (i.e. the current being leaked by the shunt needs to be negligible in comparison to the one going through the diodes). Similarly, the light I-V curve does not show any degradation for slightly shunted devices, being affected by the shunt only when the leaked current is similar to the photogenerated one. Conversely, the shunt effect is clearly visible in the dark I-V curve even for slightly shunted devices. This makes it possible to predict and anticipate the solar cell degradation before it becomes noticeable in the light I-V.

It should be mentioned that the light I-V curve could be transformed into the dark I-V curve to detect shunt resistances after some mathematical treatment (i.e. subtraction of the photogenerated current). However, the shunt influence of each subcell in the light I-V curve will depend on the illumination impinging each subcell (as previously demonstrated), making it a spectrum-dependent measurement. On the other hand, dark I-V curves show the device performance under a perfect spectral matching (i.e. same current flowing through all subcells), which 
makes it easier to assess the influence of shunts and their time evolution. However, the translation from dark I-V curves to illumination ones is not straight forward as the current distribution might change notably from one subcell to another (changing consequently the influence of the different parameters/devices in the equivalent circuit, specially the influence of the sheet resistances) [32]. This should be considered to decide whether a shunt observed in the dark I-V will have an actual effect on the illumination I-V curve.

Therefore, dark I-V curves are an excellent tool to distinguish whether any of the aforementioned effects (observed in illuminated I-V curves) are caused by shunts or not. This should be kept in mind in order to avoid wasting time and effort characterizing the solar cells under hundreds or thousands of suns which may not provide useful information of the underlying degradation phenomena.
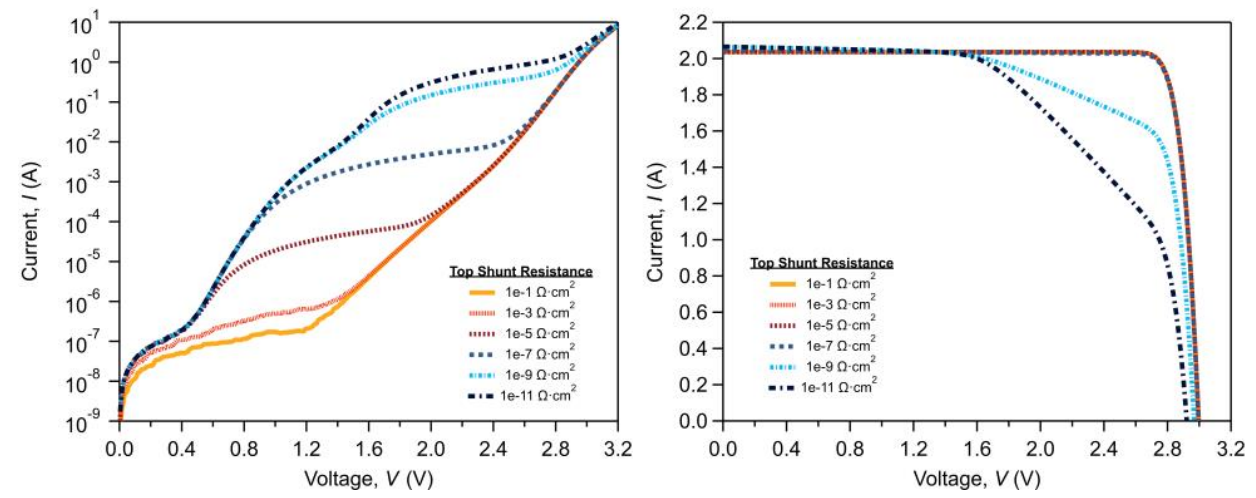

Figure 7. Simulated dark (left) and illumination (500x) I-V (right) curves of a triple junction solar cell shunted beneath two external connections as depicted in Figure 8 (left). Only three curves are distinguishable in the illumination I-V (right) as only the lowest two shunts are low enough to drain a significant amount of current at 500x.

\subsection{Electroluminescence of partially shunted solar cells}

The impact of shunts in the EL measurement of a MJSC is analyzed now in order to provide guidelines to carry out the measurement. Up to now, subcells homogeneously shunted have been analyzed. However, in order to evaluate more realistic situations we analyze the simulated EL pattern of two case studies (see Figure 8):

- Degradation in the top subcell under some bonded wires caused by a defective manufacture process.

- Degraded area in the middle subcell, for instance, as a consequence of problems in the epitaxial process.
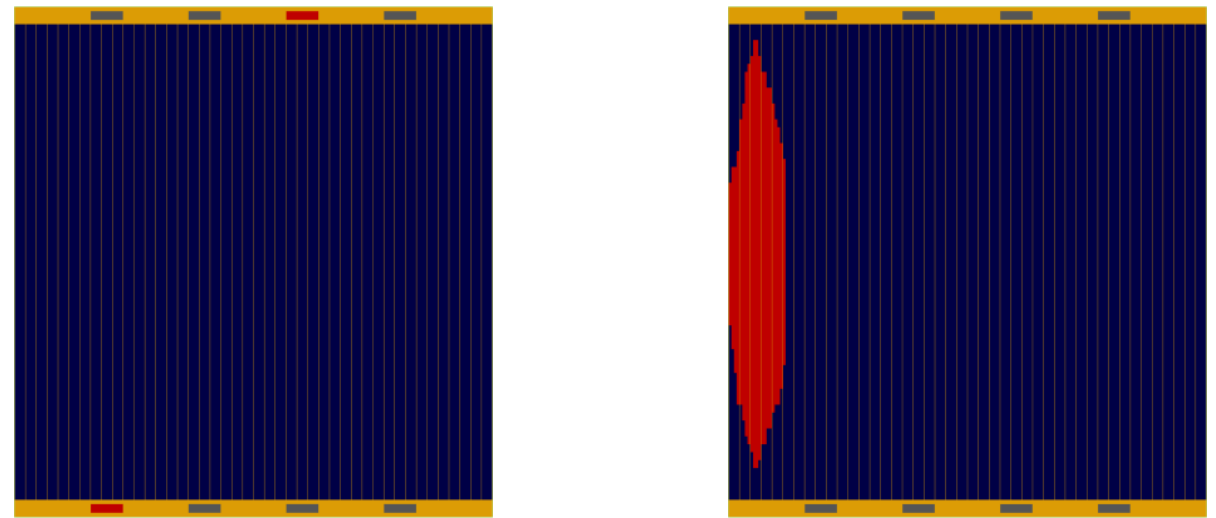

Figure 8. Front "view" of the solar cells for the EL simulation (the degraded areas are shown in red). Left: MJSC with the top subcell shunted beneath two external connections (bonding wires). Right: MJSC with the middle subcell shunted in the left side.

Degraded areas have been simulated as a decrease in the shunt resistance from $10^{6} \Omega \cdot \mathrm{cm}^{2}$ to $10^{-11} \Omega \cdot \mathrm{cm}^{2}$. Then, the whole MJSC has been forward biased and the electroluminescence pattern has been obtained by means of the voltage difference at the edges of each subcell [33-35]. In order to determine which measurement conditions reveal the shunted area more clearly, unitary EL maps have been plotted (see Figure 9 and Figure 10). 
In both cases, we can distinguish three voltage ranges. At low voltages, only the shunted subcell shows the effect of the shunted area, being the other two subcells unaffected and showing a homogeneous EL. At medium voltages the shunt influence can be observed in all the subcells. Finally, for high voltages the drained current is no longer representative in comparison to the overall current passing through the whole MJSC. Although the most noticeable differences are shown at very low voltages, it has to be pointed out that EL at these voltages would be rather low. Therefore, measurements at medium voltages would be more suitable for an experimental EL setup, where the emission needs to be high enough to be detected by the camera. At medium voltages the EL in the other subcells, rather than just the shunted one, can be used in order to detect the shunted area. Consequently, the detection of leakage currents can be carried out at any of the subcells in a MJSC. A decreased in the EL throughout the shunted area will be measured in the shunted subcell while detecting an EL signal increase in the same area for the nonshunted subcells. Moreover, the EL pattern is sharper for low bandgap subcells. We relate this behavior to the relation between the EL and the subcell voltage ratio. For low bandgap subcells the same voltage increment to allow a higher current going through, has a much higher relative contribution than for a high bandgap subcell and thus, it is more noticeable. It is also important to note that all series resistances (sheet resistances in particular) might play an important role on the current distribution.

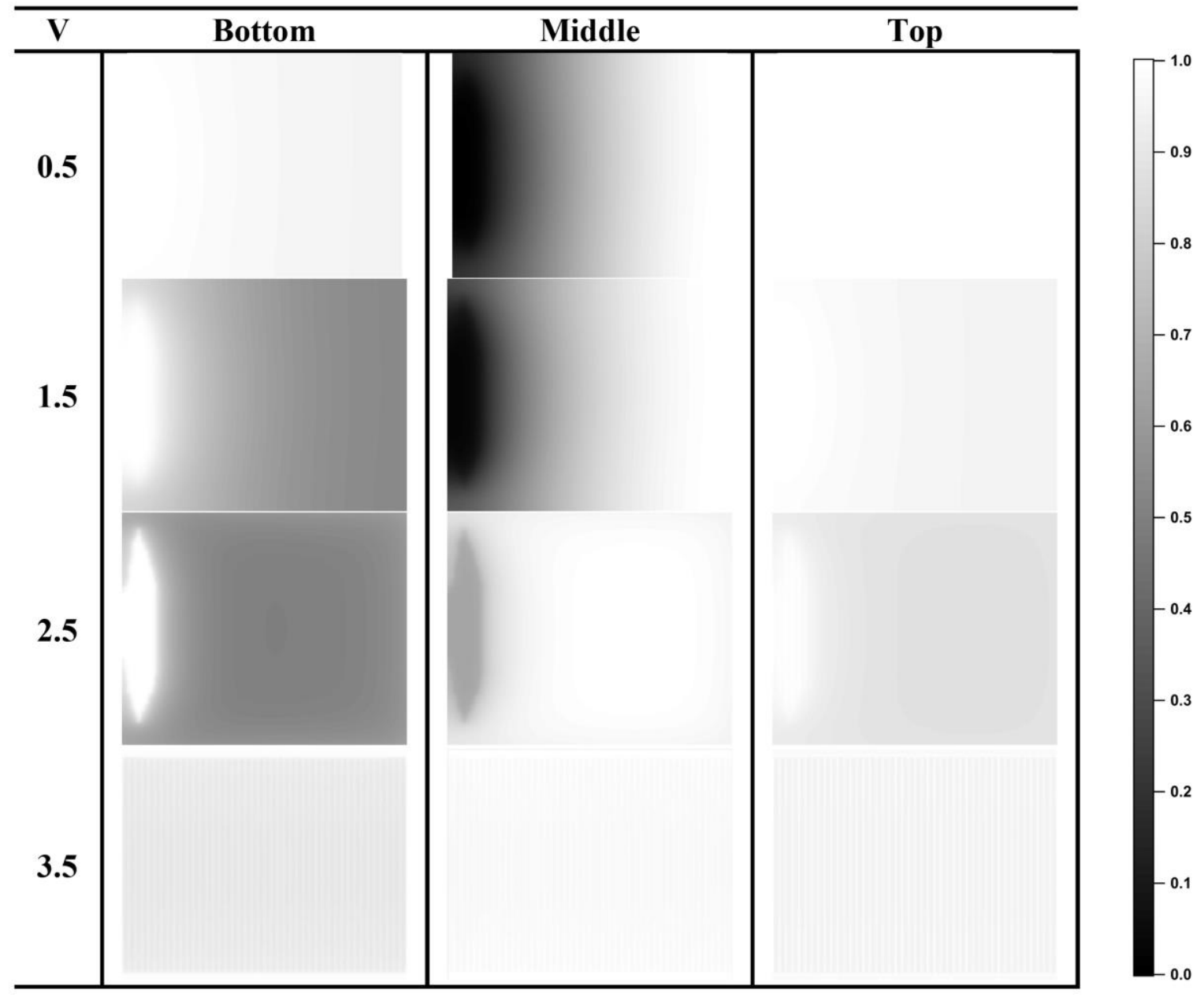

Figure 9. Simulated EL maps of each subcell inside a triple junction biased at different voltages with a shunted area in the middle subcell. 


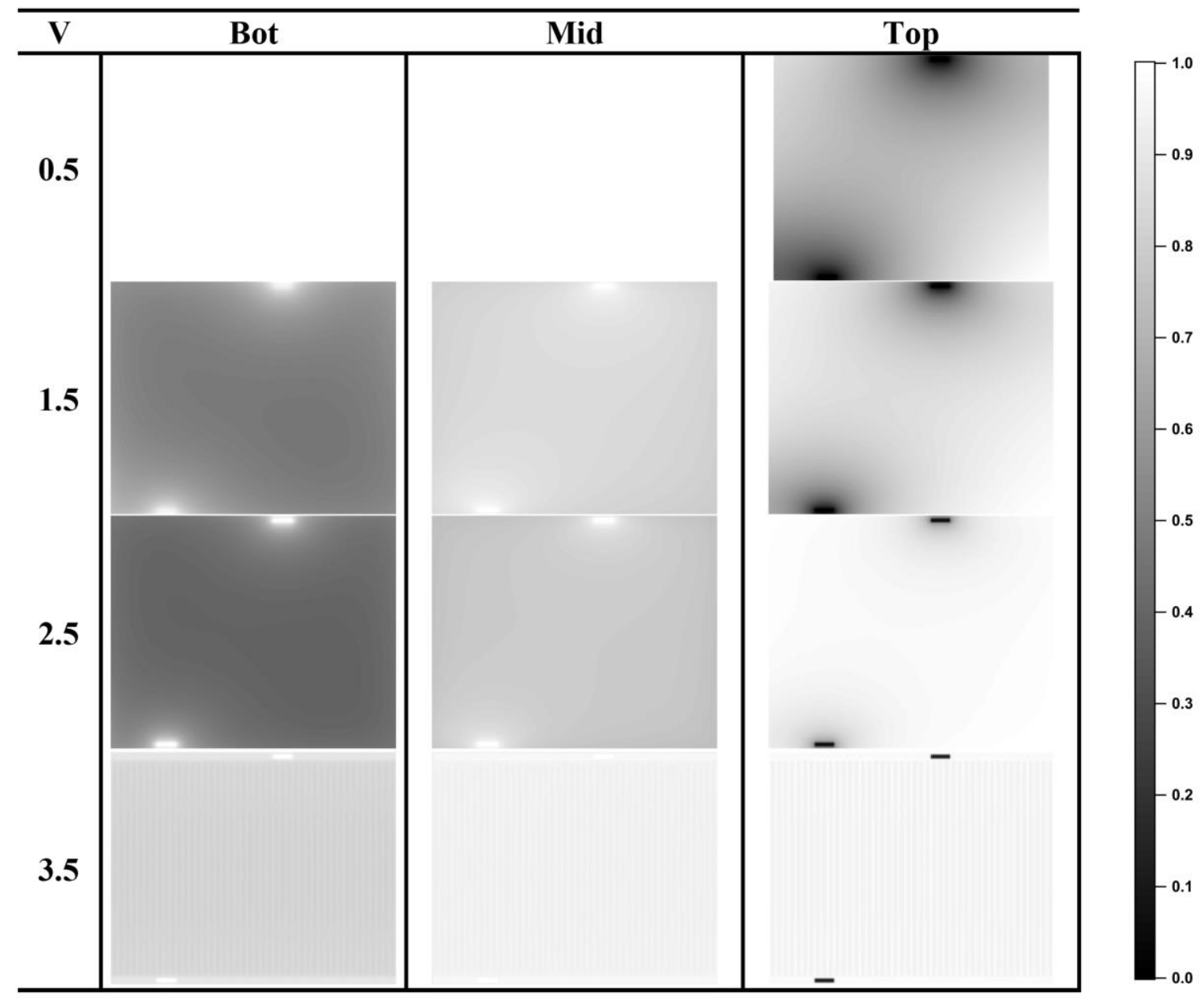

Figure 10. Simulated EL maps of each subcell inside a triple junction biased at different voltages with a shunted area beneath two bonded wires in the top subcell.

\section{DISCUSSION}

The influence of shunts inside partially shunted solar cells has been proved to notably differ from the one predicted by single junction models (completely shunted solar cell). Shunt effects become noticeable once the shunted subcell becomes the one limiting the current generation in the MJSC. If the shunted subcell is still limiting the current when it is at $0 \mathrm{~V}$, it will be reversed biased by the rest of subcells increasing its current generation. Whether the shunt will get to be seen at the $I_{\mathrm{SC}}$ operation of the MJSC or not will depend on different factors such as the photogeneration current of each subcell, the generated voltage by the non-shunted subcells or the shunting degree of the shunted subcell [7]. In any case, the shunt will always be noticeable beyond the sum of the $V_{\mathrm{OC}}$ of the non-shunted subcells, which is unexpected from the single junction models. Moreover, the dip caused in the FF of the MJSC by a shunted subcell is strongly related to the contribution to the total $V_{\mathrm{OC}}$ of the shunted subcell (see Appendix A). The lower the contribution to the $V_{\mathrm{OC}}$, the lower the dip in the FF. This makes the effect of shunted subcell more deceptive, as the I-V curve will resemble an increase in the series resistance of the device together with a $V_{\mathrm{OC}}$ loss instead of a slope change around the $I_{\mathrm{SC}}$ operation point. This is observed for the Ge subcell which does not degrade the FF of a standard triple junction below $80 \%$ no matter how shunted it is, even if its photogeneration at $500 \times$ is halved, due to its low contribution to the total $V_{\mathrm{OC}}$. The performance of a MJSC with one subcell shunted under concentration shows deceiving effects as well as an unpredicted evolution of FF and $V_{\mathrm{OC}}$. This is a consequence of the shunt dominating the subcell for low illuminations, losing influence as the concentration increases. The evolution of the FF and the $V_{\mathrm{OC}}$ of a multijunction with a shunted subcell resembles at a given range 
of concentrations the performance of a series resistance limited solar cell, while it is actually reaching the current injection levels for which the shunted subcell dominates the FF. Therefore, measurements under illumination are not useful to easily identify the presence of shunts in MJSCs.

Conversely, simulations have shown that dark I-V and EL are useful experimental techniques for the detection of shunts in MJSCs. Dark I-V curves are sensitive to even small shunts, allowing for an early-detection and improving the assessment and prediction of failures. On the other hand, EL allows to discern where the shunt is and in which subcell. Although low voltages have been shown to provide the sharpest luminescence differences between the shunted and non-shunted areas, higher voltages are desired for practical reasons (the camera needs a minimum light intensity to be able to detect it).

\section{CONCLUSIONS}

In this work the impact of shunts on MJSCs has been analyzed, pointing out the major differences between partially shunted and completely shunted solar cells. The misunderstanding between these two types of degraded solar cells leads to misinterpretation of the effects of shunts in MJSCs and therefore, the typical rules of thumb used in single junction solar cells are no longer applicable. The effect of shunts depending on the shunted subcell is shown as well as its impact in upcoming MJSCs. Deceiving effects in light I-V curve under different circumstances have been shown. Finally, the detection of shunts has been assessed by means of dark I-V or EL simulations, pointing out the importance of these techniques in order to determine the degradation of a MJSC.

\section{ACKNOWLEDGMENTS}

This work has been supported by the Spanish MINECO through the project TEC2017-83447-P, by the Comunidad de Madrid through the project MADRID-PV2 (S2018/EMT-4308) and by the Universidad Politécnica de Madrid with the project RP150910B12. I. Lombardero is funded by the Spanish MINECO through an FPU14. $\mathrm{V}$. Orlando is acknowledged for providing the I-V curves measurements of shunted solar cells which motivated this study.

\section{APPENDIX A: MAXIMUM INFLUENCE OF A SHUNTED SUBCELL ON THE OVERALL FF OF AN IDEAL MJSC}

The maximum $F F$ degradation caused by a shunt has been calculated for an ideal MJSC under the following assumptions:

1. Non-shunted solar cells have a $F F$ of $100 \%$ (i.e. their illumination I-V curve is a square).

2. All the subcells are current matched. Therefore, there is no $I_{\mathrm{SC}}$ increase due to the leakage current.
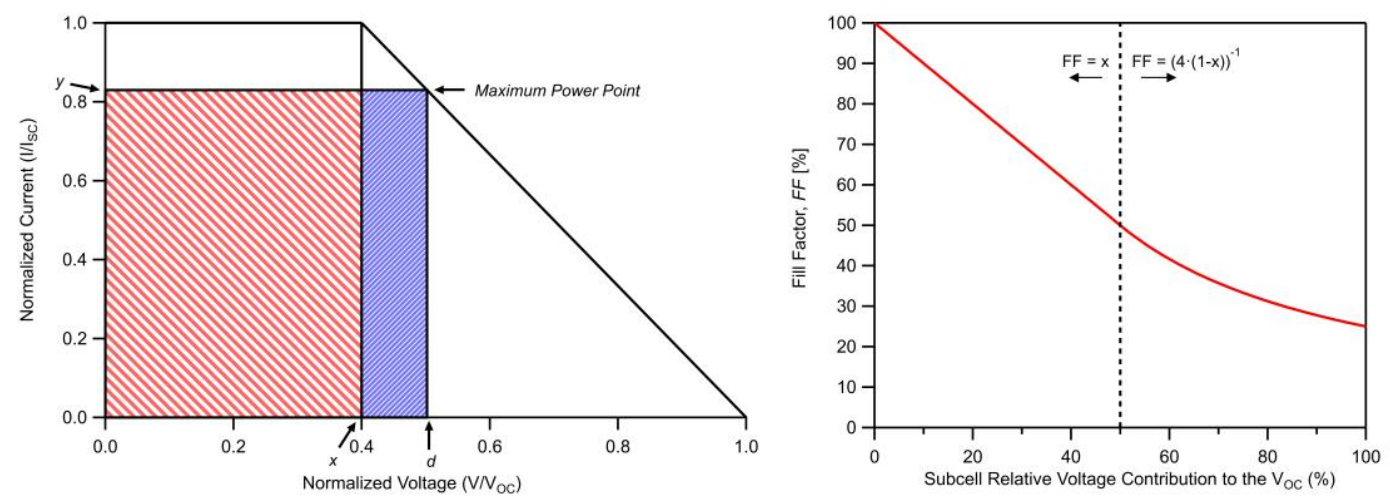

Figure 11. Left: Schematics of the illumination I-V curve used to calculate $F F$ degradation. Voltage and current values have been normalized for the sake of simplicity. The red dashed area remarks the power generated by the ideal subcells while the blue patterned one shows the power generated by the shunted subcell. Right: Evolution of the maximum FF degradation due to a shunt in one of the subcells as a function of its contribution to the total $V_{\mathrm{OC}}$. 
From Figure 11 it can be clearly seen that:

$$
d=x+(1-y) \cdot(1-x)
$$

And the total area (i.e. the power generation) is:

$$
A_{T}=d \cdot V_{\mathrm{OC}} \cdot y \cdot I_{\mathrm{SC}}=V_{\mathrm{OC}} \cdot I_{\mathrm{SC}} \cdot y \cdot(x+(1-y) \cdot(1-x))=V_{\mathrm{OC}} \cdot I_{\mathrm{SC}} \cdot\left(y-y^{2} \cdot(1-x)\right)
$$

Then, the maximum power generation can be calculated as:

$$
\frac{d A_{\mathrm{T}}}{d y}=V_{\mathrm{OC}} \cdot I_{\mathrm{SC}} \cdot(1-2 y \cdot(1-x)) \stackrel{\frac{d A_{\mathrm{T}}}{d y}=0}{\longrightarrow} y=\frac{1}{2 \cdot(1-x)}\left\{\begin{array}{r}
x \leq 0.5 \rightarrow y \leq 1 \rightarrow y=\frac{1}{2 \cdot(1-x)} \\
x>0.5 \rightarrow y>1 \rightarrow y=1
\end{array}\right.
$$

Two different solutions are found depending on the relative contribution to the total $V_{\mathrm{OC}}$ of the non-shunted subcells. If it is lower than half of it (i.e. $x \leq 0.5)$ the current at the maximum power point is lower than $I_{\mathrm{SC}}$. On the other hand, if their voltage contribution is higher than half of the total $V_{\mathrm{OC}}$ (i.e. $x \geq 0.5$ ) the mathematical equations try to achieve a current higher than $I_{\mathrm{SC}}$ (cause by a negative $d$ ). As this is not possible from a physical point of view, the $y$ value is fixed to one under such circumstances. Taking this into account we can obtain the maximum $F F$ degradation as follows:

$$
F F=\frac{A_{\mathrm{T}}}{V_{\mathrm{OC}} \cdot I_{S C}}=\left(y-y^{2} \cdot(1-x)\right)\left\{\begin{aligned}
y=\frac{1}{2 \cdot(1-x)} & \rightarrow F F=\frac{1}{4 \cdot(1-x)} \\
y=1 & \rightarrow F F=x
\end{aligned}\right.
$$

From this demonstration we can obtain several conclusions. For multijunction solar cells with a shunted subcell contributing with less than half of the total $V_{\mathrm{OC}}$, the maximum $F F$ decrease is equivalent to the voltage contribution of the non-shunted subcells (for ideal solar cells). Moreover, the operation point for the multijunction would be the one of the non-shunted subcells, and that is why the current is $I_{\mathrm{SC}}$. On the other hand, for multijunction solar cells with a shunted subcell contributing with more than half of the total $V_{\mathrm{OC}}$, the $F F$ decrease is hyperbolic from $50 \%$ at $\mathrm{x}=0.5$ to $25 \%$ at $\mathrm{x}=0$. These two trends (which matches at $\mathrm{x}=0.5$ ) are shown in Figure 11. As it was expected, the maximum degradation achievable for the $F F$ is a $25 \%$ when the shunted subcell is the only one contributing to the $V_{\mathrm{OC}}$ (single junction solar cell) whereas for most multijunctions (except for tandem structures or certain triple junctions when the shunted subcell is the one with the highest bandgap) the maximum $F F$ decrease is the same (in percentage) as the voltage contribution of the shunted subcell.

\section{REFERENCES}

[1] M. Meusel, C. Baur, G. Létay, A.W. Bett, W. Warta, E. Fernandez, Spectral response measurements of monolithic GaInP/Ga(In)As/Ge triple-junction solar cells: Measurement artifacts and their explanation, Prog. Photovoltaics Res. Appl. 11 (2003) 499-514. doi:10.1002/pip.514.

[2] J.-J. Li, C.R. Allen, S.H. Lim, Y.-H. Zhang, Elimination of Artifacts in External Quantum Efficiency Measurements for Multijunction Solar Cells Using a Pulsed Voltage Bias, IEEE J. Photovoltaics. 3 (2013) 769-775. doi:10.1109/JPHOTOV.2013.2242959.

[3] E. Barrigón, P. Espinet-González, Y. Contreras, I. Rey-Stolle, Implications of low breakdown voltage of component subcells on external quantum efficiency measurements of multijunction solar cells, Prog. Photovoltaics Res. Appl. 23 (2015) 1597-1607. doi:10.1002/pip2597.

[4] M. Pravettoni, R. Galleano, A. Virtuani, H. Müllejans, E.D. Dunlop, Spectral response measurement of double-junction thin-film photovoltaic devices: the impact of shunt resistance and bias voltage, Meas. Sci. Technol. 22 (2011) 10. doi:10.1088/0957-0233/22/4/045902.

[5] V. Paraskeva, M. Hadjipanayi, M. Norton, M. Pravettoni, G.E. Georghiou, The effect of shunt resistance on External Quantum Efficiency measurements at high light bias conditions, in: 2014 IEEE 40th Photovolt. Spec. Conf., IEEE, 2014: pp. 3664-3669. doi:10.1109/PVSC.2014.6924902.

[6] E.D. Filimonov, S.A. Kozhukhovskaia, M.A. Mintairov, M.Z. Shvarts, Analysis of a multi-junction solar cell with shunted subcells using SPICE, J. Phys. Conf. Ser. 690 (2016) 012040. doi:10.1088/1742- 
6596/690/1/012040.

[7] A. Braun, N. Szabó, K. Schwarzburg, T. Hannappel, E.A. Katz, J.M. Gordon, Current-limiting behavior in multijunction solar cells, Appl. Phys. Lett. 98 (2011). doi:10.1063/1.3596444.

[8] J. Wohlgemuth, W. Herrmann, Hot Spot Tests for Crystalline Silicon Modules, IEEE Conf. Photovolt. Spec. (2005) 1062-1063. doi:10.1109/PVSC.2005.1488317.

[9] F. Oviedo, Z. Liu, Z. Ren, M. Thway, T. Buonassisi, I.M. Peters, Ohmic shunts in two-terminal dualjunction solar cells with current mismatch, Jpn. J. Appl. Phys. 56 (2017) 08MA05. doi:10.7567/JJAP.56.08MA05.

[10] I. Lombardero, C. Algora, Impact of shunt resistance on the assessment of multijunction I-V, in: $2018:$ p. 060001. doi:10.1063/1.5053525.

[11] I. Garcia, P. Espinet-González, I. Rey-Stolle, E. Barrigón, C. Algora, F. Dimroth, S. Kurtz, G. Sala, A.W. Bett, Extended Triple-Junction Solar Cell 3D Distributed Model: Application to Chromatic AberrationRelated Losses, 16 (2011) 13-16. doi:10.1063/1.3658284.

[12] B. Galiana, C. Algora, I. Rey-Stolle, I. Vara, A 3-D Model for Concentrator Solar Cells Based on Distributed Circuit Units, IEEE Trans. Electron Devices. 52 (2005) 2552-2558. doi:10.1109/TED.2005.859620.

[13] O. Breitenstein, J. Bauer, T. Trupke, R.A. Bardos, On The Detection of Shunts in Silicon Solar Cells by Photo- and Electroluminescence Imaging, Prog. Photovoltaics Res. Appl. 16 (2008) 325-330.

doi:10.1002/pip803.

[14] I. Rey-Stolle, C. Algora, Modeling of the resistive losses due to the bus-bar and external connections in IIIV high-concentrator solar cells, IEEE Trans. Electron Devices. 49 (2002) 1709-1714. doi:10.1109/TED.2002.803638.

[15] B. Galiana, C. Algora, I. Rey-Stolle, Comparison of 1D and 3D analysis of the front contact influence on GaAs concentrator solar cell performance, Sol. Energy Mater. Sol. Cells. 90 (2006) 2589-2604. doi:10.1016/j.solmat.2006.02.013.

[16] I. Garcia, C. Algora, I. Rey-Stolle, B. Galiana, Study of non-uniform light profiles on high concentration IIIV solar cells using quasi-3D distributed models, Conf. Rec. IEEE Photovolt. Spec. Conf. (2008) 3-8. doi:10.1109/PVSC.2008.4922908.

[17] P. Espinet-González, I. Rey-Stolle, M. Ochoa, C. Algora, I. García, E. Barrigón, Analysis of perimeter recombination in the subcells of GaInP/GaAs/Ge triple-junction solar cells, Prog. Photovoltaics Res. Appl. 23 (2015) 874-882. doi:10.1002/pip.2501.

[18] P. Espinet, I. García, I. Rey-Stolle, C. Algora, M. Baudrit, Extended description of tunnel junctions for distributed modeling of concentrator multi-junction solar cells, Sol. Energy Mater. Sol. Cells. 95 (2011) 2693-2697. doi:10.1016/j.solmat.2011.05.009.

[19] P. Espinet González, Advances in the modeling, characterization and reliability of concentrator multijunction solar cells, Universidad Politécnica de Madrid, 2012. http://oa.upm.es/14620/.

[20] Silvaco SmartSpice ${ }^{\mathrm{TM}}, 4$.28.2.R, (2017) 1247. https://www.silvaco.com/products/analog_mixed_signal/smartspice.html.

[21] O. Breitenstein, J.P. Rakotoniaina, M.H. Al Rifai, Quantitative Evaluation of Shunts in Solar Cells by LockIn Thermography, Prog. Photovoltaics Res. Appl. 11 (2003) 515-526. doi:10.1002/pip.520.

[22] F. Dimroth, T.N.D. Tibbits, M. Niemeyer, F. Predan, P. Beutel, C. Karcher, E. Oliva, G. Siefer, D. Lackner, P. Fus-Kailuweit, A.W. Bett, R. Krause, C. Drazek, E. Guiot, J. Wasselin, A. Tauzin, T. Signamarcheix, Four-junction wafer-bonded concentrator solar cells, IEEE J. Photovoltaics. 6 (2016) 343-349. doi:10.1109/JPHOTOV.2015.2501729.

[23] J.F. Geisz, M.A. Steiner, N. Jain, K.L. Schulte, R.M. France, W.E. McMahon, E.E. Perl, D.J. Friedman, Building a Six-Junction Inverted Metamorphic Concentrator Solar Cell, IEEE J. Photovoltaics. 8 (2018) 626-632. doi:10.1109/JPHOTOV.2017.2778567.

[24] N. Miyashita, Y. He, N. Ahsan, T. Agui, H. Juso, T. Takamoto, Y. Okada, Incorporation of hydrogen into MBE-grown dilute nitride GaInNAsSb layers in a MOCVD growth ambient, Sol. Energy Mater. Sol. Cells. 185 (2018) 359-363. doi:10.1016/j.solmat.2018.05.043.

[25] M. Meusel, R. Adelhelm, F. Dimroth, A.W. Bett, W. Warta, Spectral mismatch correction and spectrometric characterization of monolithic III-V multi-junction solar cells, Prog. Photovoltaics Res. Appl. 10 (2002) 243-255. doi:10.1002/pip.407.

[26] C. Dominguez, I. Anton, G. Sala, Multijunction solar cell model for translating I-V characteristics as a function of irradiance, spectrum, and cell temperature, Prog. Photovoltaics Res. Appl. 18 (2010) $272-284$. 
doi:10.1002/pip.965.

[27] C. Dominguez, I. Antón, G. Sala, S. Askins, Current-matching estimation for multijunction cells within a CPV module by means of component cells, Prog. Photovolt Res. Appl. 15 (2007) 659-676. doi:10.1002/pip2227.

[28] M.A. Green, Solar cell fill factors: General graph and empirical expressions, Solid State Electron. 24 (1981) 788-789. doi:10.1016/0038-1101(81)90062-9.

[29] H. Nesswetter, P. Lugli, A.W. Bett, C.G. Zimmermann, Electroluminescence and photoluminescence characterization of multijunction solar cells, IEEE J. Photovoltaics. 3 (2013) 353-358. doi:10.1109/JPHOTOV.2012.2213801.

[30] V. Orlando, M. Gabás, B. Galiana, P. Espinet-González, S. Palanco, N. Nuñez, M. Vázquez, K. Araki, C. Algora, Failure analysis on lattice matched GaInP/Ga(In)As/Ge commercial concentrator solar cells after temperature accelerated life tests, Prog. Photovolt Res. Appl. (2016). doi:10.1002/pip.2818.

[31] C.G. Zimmermann, Performance Mapping of Multijunction Solar Cells Based on Electroluminescence, IEEE Electron Device Lett. 30 (2009) 825-827. doi:10.1109/LED.2009.2024335.

[32] B. Galiana, C. Algora, I. Rey-Stolle, Explanation for the dark I-V curve of III-V concentrator solar cells, Prog. Photovoltaics Res. Appl. 16 (2008) 331-338. doi:10.1002/pip.805.

[33] U. Rau, Reciprocity relation between photovoltaic quantum efficiency and electroluminescent emission of solar cells, Phys. Rev. B. 76 (2007) 085303. doi:10.1103/PhysRevB.76.085303.

[34] T. Kirchartz, U. Rau, M. Hermle, A.W. Bett, A. Helbig, J.H. Werner, Internal voltages in GaIn/PGaInAs/Ge multijunction solar cells determined by electroluminescence measurements, Appl. Phys. Lett. 92 (2008) 9093. doi:10.1063/1.2903101.

[35] J.F. Geisz, M.A. Steiner, I. Garcia, R.M. France, W.E. McMahon, C.R. Osterwald, D.J. Friedman, Generalized Optoelectronic Model of Series-Connected Multijunction Solar Cells, IEEE J. Photovoltaics. 5 (2015) 1827-1839. doi:10.1109/JPHOTOV.2015.2478072. 